\title{
Peripartum and neonatal factors associated with the persistence of neonatal brachial plexus palsy at 1 year: a review of 382 cases
}

\author{
*Thomas J. Wilson, MD, ${ }^{1}$ Kate W. C. Chang, MA, MS, ${ }^{1}$ Suneet P. Chauhan, MD, ${ }^{2}$ and \\ Lynda J. S. Yang, MD, PhD'1 \\ 'Department of Neurosurgery, University of Michigan, Ann Arbor, Michigan; and 2Department of Obstetrics, Gynecology, and \\ Reproductive Sciences, University of Texas Health Science Center, Houston, Texas
}

\begin{abstract}
OBJECTIVE Neonatal brachial plexus palsy (NBPP) occurs due to the stretching of the nerves of the brachial plexus before, during, or after delivery. NBPP can resolve spontaneously or become persistent. To determine if nerve surgery is indicated, predicting recovery is necessary but difficult. Historical attempts explored the association of recovery with only clinical and electrodiagnostic examinations. However, no data exist regarding the neonatal and peripartum factors associated with NBPP persistence.
\end{abstract}

METHODS This retrospective cohort study involved all NBPP patients at the University of Michigan between 2005 and 2015. Peripartum and neonatal factors were assessed for their association with persistent NBPP at 1 year, as defined as the presence of musculoskeletal contractures or an active range of motion that deviated from normal by $>10^{\circ}$ (shoulder, elbow, hand, and finger ranges of motion were recorded). Standard statistical methods were used.

RESULTS Of 382 children with NBPP, $85 \%$ had persistent NBPP at 1 year. A wide range of neonatal and peripartum factors was explored. We found that cephalic presentation, induction or augmentation of labor, birth weight $>9 \mathrm{lbs}$, and the presence of Horner syndrome all significantly increased the odds of persistence at 1 year, while cesarean delivery and Narakas Grade I to II injury significantly reduced the odds of persistence.

CONCLUSIONS Peripartum/neonatal factors were identified that significantly altered the odds of having persistent NBPP at 1 year. Combining these peripartum/neonatal factors with previously published clinical examination findings associated with persistence should allow the development of a prediction algorithm. The implementation of this algorithm may allow the earlier recognition of those cases likely to persist and thus enable earlier intervention, which may improve surgical outcomes.

http://thejns.org/doi/abs/10.3171/2015.10.PEDS15543

KEY WORDS neonatal brachial plexus palsy; neonatal risk factors; peripartum risk factors; peripheral nerve

$\mathrm{N}$ EONATAL brachial plexus palsy (NBPP) results from the stretching of the nerves of the brachial plexus before, during, or after delivery. This disorder occurs in approximately 0.42 to 2.9 per 1000 live births. ${ }^{3,11,14,16}$ The resulting neurological deficit depends on the portion of the brachial plexus that was injured, with the most common pattern being injury to C-5 and C-6 nerve roots (and/or upper trunk), resulting in weakness of shoulder abduction, external rotation, and elbow flexion. ${ }^{7}$ Previous studies in the literature suggest that some degree of NBPP persists in up to $70 \%$ to $80 \%$ of children born with NBPP. ${ }^{31}$ Persistent NBPP is debilitating, affecting function, development, and quality of life..$^{8,10,33}$ In these patients, early referral to and early evaluation by interdisciplinary specialty clinics is paramount to maximizing recovery.

Of significant importance for maximizing outcomes is determining which patients are likely to recover spontaneously and which patients are likely to benefit from timely surgical nerve reconstruction in the context of multidisciplinary treatment paradigms. In addition to the lack of early referrals, there is currently neither consensus in the assessment methods nor guidelines to aid clinicians in selecting patients who are likely to benefit from surgical

ABBREVIATIONS ACOG = American College of Obstetricians and Gynecologists; IRB = institutional review board; NBPP = neonatal brachial plexus palsy; UM-IBPP = University of Michigan Interdisciplinary Brachial Plexus Program.

SUBMITTED September 4, 2015. ACCEPTED October 21, 2015.

INCLUDE WHEN CITING Published online January 22, 2016; DOI: 10.3171/2015.10.PEDS15543.

* Dr. Wilson and Ms. Chang contributed equally to this work. 
intervention. ${ }^{9}$ One paradigm that has been used is the assessment of biceps function at 3 months, with the lack of recovery signifying a poor prognosis and serving as an indication for surgery. ${ }^{17,21}$ Other paradigms have focused on earlier evaluation of biceps and triceps function coupled with electrodiagnostics or other functional testing such as the "towel test" or "cookie test.", ",6,24 As opposed to the several peripartum (maternal) and neonatal characteristics that have been identified as risk factors for the occurrence of NBPP (e.g., multiparity, gestational diabetes, labor abnormalities, operative vaginal delivery, shoulder dystocia, and macrosomia), 27,36,39 no data are available regarding peripartum or neonatal factors and their relationship to the persistence of NBPP.

We aimed to identify the peripartum and neonatal factors associated with persistence of NBPP at 1 year of age. It is our hope that the identification of such factors may allow the development of a prediction scheme that incorporates these factors along with physical examination findings, electrodiagnostics, and imaging findings to identify patients unlikely to recover and, thus, be recommend for early nerve surgery.

\section{Methods \\ Study Design}

This retrospective cohort study was approved by the institutional review board (IRB) at the University of Michigan. Data from all patients included in the University of Michigan Interdisciplinary Brachial Plexus Program (UM-IBPP) data repository from July 2005 to June 2015 were retrospectively reviewed. Patients with NBPP were diagnosed via clinical presentation, physical examination, and diagnostic testing such as electromyography and/ or imaging evaluations. The UM-IBPP team evaluated infants with NBPP in order to determine their shoulder, elbow, hand, and finger active ranges of motion. Peripartum and neonatal factors were abstracted from an IRBapproved data repository. Peripartum factors comprised maternal age at delivery, parous birth, gestational diabetes, hypertension, shoulder dystocia in prior and current births, induction or labor augmentation, use of a birth aid (vacuum or forceps), duration of labor (hours), and route of delivery (vaginal or cesarean section). Neonatal factors consisted of gestational age at birth (weeks), delivery presentation (breech or cephalic), 5-minute Apgar score, birth weight $>9 \mathrm{lbs}$, clavicle fracture, humerus fracture, presence of torticollis, plagiocephaly, and Horner syndrome. Narakas grade was dichotomized into Narakas I to II and III to IV injuries.

The demographic variables were collected at the time of clinical evaluation. The ZIP code of the referring provider was used to find the median household income by accessing the United States Census Bureau data from 2013.

\section{Outcome of Interest}

The primary outcome of interest was NBPP persistence, defined as the presence of musculoskeletal contractures or any joint's active range of motion that deviated from normal by more than $10^{\circ}$ or any patient undergoing nerve surgery for NBPP using our management algorithm
(Fig. 1). Patients undergoing nerve surgery are, by definition, considered to have persistent NBPP according to our management algorithm. Persistence was evaluated at 1 year of age.

\section{Statistical Analysis}

Statistical analysis was performed using commercially available software (SPSS version 22; IBM Corp.). The Student t-test (continuous variables) and chi-square test or Fisher exact test (categorical variables) were used to investigate differences in the peripartum and neonatal characteristics between infants with persistent and resolved NBPP at 1 year of age. For those variables with a statistically significant difference $(\mathrm{p}<0.05)$, we further analyzed them using univariate logistic regression. For all tests, a p value $<0.05$ was considered statistically significant.

\section{Results}

During the study period, 394 infants with NBPP were seen by the UM-IBPP team, and 382 infants received follow-up through 1 year and were included in the study. At 1 year, $323(84.6 \%)$ of the infants in the specialty referral clinic had persistent NBPP. While traditionally associated with birth trauma during vaginal delivery, 30 (7.9\%) infants were born by cesarean delivery. Maternal and peripartum factors were then tested for their association with the persistence of NBPP at 1 year. Table 1 demonstrates the demographic characteristics of the patients included in this study.

Table 2 demonstrates the peripartum factors that were tested for their association with persistence of NBPP at 1 year. No association was seen for shoulder dystocia with prior or current birth, nor maternal age, diabetes, hypertension, primiparous birth, or duration of labor. The following factors were associated $(\mathrm{p}<0.05)$ with NBPP persistence: cephalic presentation, induction or augmentation of labor, the use of a birth aid (vacuum or forceps), and vaginal delivery.

Table 3 demonstrates the neonatal factors that were evaluated for their association with persistence of NBPP at 1 year. No association was seen between persistent NBPP and clavicle or humerus fracture, torticollis, plagiocephaly, or gestational age. However, birth weight > 9 lbs, Apgar score $<7$ at 5 minutes, presence of Horner syndrome, and Narakas grade were all associated with NBPP persistence at 1 year.

Next, we determined the odds ratio of having persistent NBPP at 1 year by applying univariate logistic regression modeling. Table 4 demonstrates the results. Cephalic presentation, induction or augmentation of labor, birth weight $>9 \mathrm{lbs}$, and the presence of Horner syndrome all significantly increased the likelihood of persistence at 1 year. To the contrary, cesarean delivery and a Narakas Grade I to II injury both significantly reduced the likelihood of persistent NBPP at 1 year.

\section{Discussion}

A number of previous studies have focused on the identification of the factors associated with the incidence of NBPP. However, no data exist regarding what factors are 


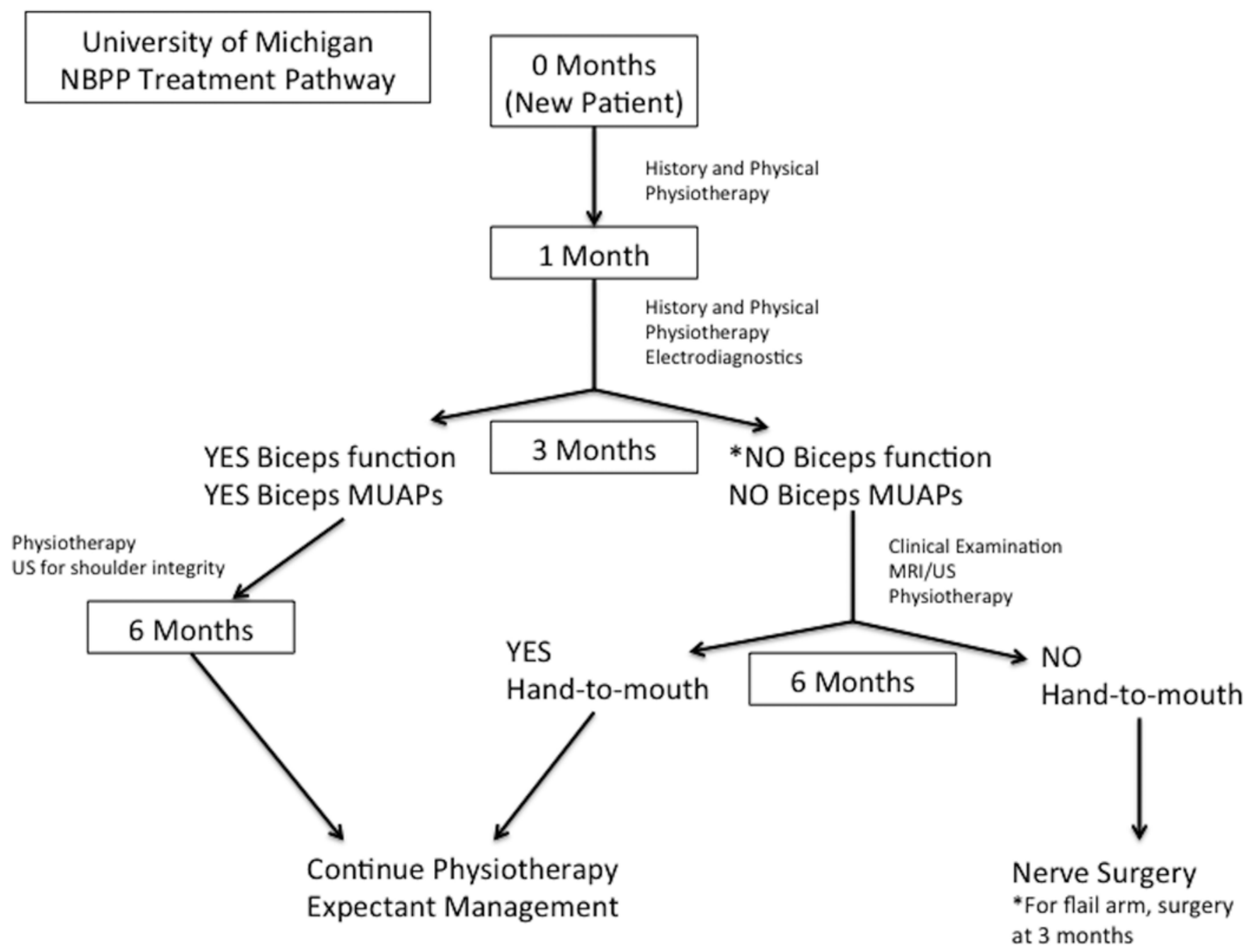

FIG. 1. The management algorithm used by UM-IBPP for the management of newly referred patients. MUAPs = motor unit action potentials; US = ultrasonography.

associated with persistent versus spontaneously resolved NBPP. In this study, we aimed to identify the peripartum and neonatal factors that were associated with persistent NBPP. We found that cephalic presentation, induction or augmentation of labor, birth weight $>9 \mathrm{lbs}$, and the presence of Horner syndrome all significantly increased the odds of persistence at 1 year, while cesarean delivery and Narakas Grade I to II injury significantly reduced the odds of persistence.

NBPP is not uncommon, occurring in approximately 1.5 per 1000 live births, similar to the incidence of cerebral palsy. The literature varies widely regarding what percentage of NBPP patients experiences spontaneous resolution, but most methodologically sound studies suggest that a deficit persists in $20 \%$ to $30 \%$ of patients, though there is variance in how persistence is defined and the number may be higher. ${ }^{22,31}$ For example, using rigid criteria in the current study, we found persistence in $85 \%$ of patients. Our data may be biased, however, as those patients who rapidly and spontaneously resolve are unlikely to be referred to specialty centers such as ours. Nerve surgery is underutilized for patients with NBPP. Only approximately
$3.3 \%$ of patients with NBPP undergo some form of nerve surgery, ${ }^{34}$ despite an at least 10 -fold higher rate of persistence. This may reflect a lack of knowledge concerning nerve surgery by referring providers, or may reflect the difficulty in deciding to whom nerve surgery should be offered. When neonates present with NBPP, the clinician is left with the decision of whether to offer nerve surgery or manage conservatively and allow spontaneous recovery. There are few data available addressing the indications for nerve reconstruction, and no specific guidelines are available to the clinician faced with this decision.

A number of paradigms have been developed in an attempt to create a decision-making protocol, but none has become the standard of care. Most agree that when a neurotmetic lesion or nerve root avulsion can be identified, that is an indication for early nerve surgery. ${ }^{22,41}$ However, in the absence of a neurotmetic lesion or root avulsion, practice varies. Most management strategies have focused on evaluation by physical examination, or functional examination using the progress in the examination over time to dictate whether operative management is pursued. Impaired hand function at 2 to 3 months of age is seen by some as an in- 
TABLE 1. Demographic characteristics of patients included in this study*

\begin{tabular}{|c|c|c|c|c|}
\hline Variable & Entire Cohort $(n=382)$ & Persistent NBPP $(n=323)$ & Resolved NBPP $(n=59)$ & p Value \\
\hline Sex & & & & 0.019 \\
\hline Male & $186 / 382(49 \%)$ & $149 / 323(46 \%)$ & $37 / 59(63 \%)$ & \\
\hline Female & $196 / 382(51 \%)$ & $174 / 323(54 \%)$ & $22 / 59(37 \%)$ & \\
\hline Race & & & & 0.024 \\
\hline White & $262 / 358(73 \%)$ & $217 / 302(72 \%)$ & $45 / 56(80 \%)$ & \\
\hline African American & $61 / 358(17 \%)$ & $58 / 302(19 \%)$ & $3 / 56(5 \%)$ & \\
\hline Other & $35 / 358(10 \%)$ & $27 / 302(9 \%)$ & $8 / 56(14 \%)$ & \\
\hline Median household income (range) & $\$ 42,482(\$ 12,262-\$ 123,771)$ & $\$ 42,133(\$ 12,262-\$ 123,771)$ & $\$ 44,424(\$ 24,572-\$ 87,740)$ & 0.198 \\
\hline Mean referral age, mos. (SD) & $27(52)$ & $32(6)$ & $3(4)$ & $<0.001$ \\
\hline Referral specialty/specialist & & & & 0.891 \\
\hline Pediatrics & $235 / 331(71 \%)$ & $197 / 280(70 \%)$ & $38 / 51(75 \%)$ & \\
\hline Neurology & $23 / 331(7 \%)$ & $20 / 280(7 \%)$ & $3 / 51(6 \%)$ & \\
\hline Physician (other) & $17 / 331(5 \%)$ & $14 / 280(5 \%)$ & $3 / 51(6 \%)$ & \\
\hline Orthopedics & $14 / 331(4 \%)$ & $12 / 280(4 \%)$ & $2 / 51(4 \%)$ & \\
\hline Physiatry & $12 / 331(4 \%)$ & $10 / 280(4 \%)$ & $2 / 51(4 \%)$ & \\
\hline Family practice & $12 / 331(4 \%)$ & $12 / 280(4 \%)$ & $0 / 51(0 \%)$ & \\
\hline Occupational/physical therapist & $8 / 331(2 \%)$ & $7 / 280(3 \%)$ & $1 / 51(2 \%)$ & \\
\hline Self & $5 / 331(2 \%)$ & $4 / 280(1.4 \%)$ & $1 / 51(2 \%)$ & \\
\hline Neurosurgery & $2 / 331(0.6 \%)$ & $1 / 280(0.4 \%)$ & $1 / 51(2 \%)$ & \\
\hline Obstetrician/gynecologist & $2 / 331(0.6 \%)$ & $2 / 280(0.7 \%)$ & $0 / 51(0 \%)$ & \\
\hline Case manager & $1 / 331(0.3 \%)$ & $1 / 280(0.4 \%)$ & $0 / 51(0 \%)$ & \\
\hline Labor location & & & & 0.833 \\
\hline Hospital & $346 / 357(97 \%)$ & $294 / 303(97 \%)$ & $52 / 54(96 \%)$ & \\
\hline Home & $10 / 357(2.8 \%)$ & $8 / 303(2.7 \%)$ & $2 / 54(4 \%)$ & \\
\hline Other & $1 / 357(0.2 \%)$ & $1 / 303(0.3)$ & $0 / 54(0 \%)$ & \\
\hline Delivery physician & & & & 0.368 \\
\hline Obstetrician/gynecologist & $333 / 359(93 \%)$ & $280 / 304(92 \%)$ & $53 / 55(96 \%)$ & \\
\hline Midwife & $16 / 359(4 \%)$ & $14 / 304(5 \%)$ & $2 / 55(4 \%)$ & \\
\hline Family practice & $10 / 359(3 \%)$ & $10 / 304(3 \%)$ & $0 / 55(0 \%)$ & \\
\hline \multicolumn{5}{|l|}{ Treatment } \\
\hline Nerve surgery & $50 / 341(15 \%)$ & $50 / 289(17 \%)$ & $0 / 52(0 \%)$ & 0.001 \\
\hline Botulinum toxin & $21 / 335(6 \%)$ & $21 / 285(7 \%)$ & $0 / 50(0 \%)$ & 0.054 \\
\hline Shoulder surgery & $35 / 341(10 \%)$ & $35 / 289(12 \%)$ & $0 / 52(0 \%)$ & 0.005 \\
\hline Other orthopedic surgery & $12 / 343(3 \%)$ & $11 / 291(4 \%)$ & $1 / 52(2 \%)$ & 0.990 \\
\hline
\end{tabular}

* Denominators represent the number of patients for whom data were available for the given variable.

dication for surgery. ${ }^{30}$ Operative management is also often recommended for those infants who lack shoulder external rotation and elbow flexion by 3 to 4 months of age..$^{29}$ Given that neurotmetic lesions or root avulsions will not spontaneously recover, work has focused on the earlier identification of such lesions by imaging as a means of improving clinical decision making. ${ }^{32,35}$ Other work has focused on additional examination findings that suggest the poor likelihood of spontaneous recovery as a means of improving surgical stratification. For example, concurrent phrenic nerve palsy in patients with NBPP has been shown to portend a poor likelihood of spontaneous recovery. ${ }^{42}$ Electrodiagnostics and imaging studies are merely an extension of the physical examination and have not been shown to be predictive, but are still important adjuncts. ${ }^{5,32,37}$

The development of a prediction scheme that incorpo- rates peripartum and neonatal factors, early clinical examination findings, and early diagnostic imaging and can be applied shortly after birth may have a number of implications. First, it may improve specialty utilization and referral. Ideally, all neonates with NBPP would be referred to multidisciplinary specialty clinics for care, but specialty care for NBPP is underutilized. ${ }^{34}$ Currently, no test or prediction algorithm exists based on peripartum and neonatal factors for the identification of severe lesions. ${ }^{23}$ In fact, few treatment paradigms for NBPP even exist, and those that do use serial physical examination information, not the characteristics inherent to the perinatal period. ${ }^{2,24}$ Ideally, a specialty clinic would evaluate all neonates, but the underutilization of surgical intervention suggests that early referral/evaluation is not happening. The development of such a prediction scheme may allow clinicians other 
TABLE 2. Evaluation of the association of the peripartum factors with NBPP persistence at 1 year*

\begin{tabular}{lccc}
\hline \multicolumn{1}{c}{ Variable } & Persistent NBPP $(\mathrm{n}=323)$ & Resolved NBPP $(\mathrm{n}=59)$ & $\mathrm{p}$ Value \\
\hline Mean maternal age in yrs (SD) & $28.5(6.0)$ & $29.7(6.1)$ & 0.192 \\
\hline Diabetes & $74 / 292(25.3 \%)$ & $8 / 52(15.4 \%)$ & 0.121 \\
\hline Hypertension & $53 / 283(18.7 \%)$ & $8 / 53(15.1 \%)$ & 0.529 \\
\hline Shoulder dystocia with prior birth & $19 / 180(10.6 \%)$ & $4 / 29(13.8 \%)$ & 0.605 \\
\hline Shoulder dystocia with current birth & $190 / 285(66.7 \%)$ & $26 / 48(54.2 \%)$ & 0.093 \\
\hline Primiparous & $135 / 308(43.8 \%)$ & $22 / 52(42.3 \%)$ & 0.838 \\
\hline Mean duration of labor in hrs (SD) & $12.9(10.1)$ & $13.8(16.5)$ & 0.627 \\
\hline Cephalic presentation & $292 / 304(96.1 \%)$ & $45 / 52(86.5 \%)$ & 0.005 \\
\hline Induction/augmentation of labor & $170 / 282(60.3 \%)$ & $18 / 48(37.5 \%)$ & 0.003 \\
\hline Birth aid (vacuum or forceps) & $75 / 310(24.2 \%)$ & $7 / 57(12.3 \%)$ & 0.047 \\
\hline Cesarean delivery & $18 / 323(5.6 \%)$ & $12 / 59(20.3 \%)$ & $<0.001$ \\
\hline
\end{tabular}

* Denominators represent the number of patients for whom data were available for the given variable.

than nerve surgeons to make an early assessment and may expedite referrals, rather than encouraging the oftimplemented watch-and-wait paradigm with late referral for those infants without spontaneous recovery. There is certainly selection bias in our study given that the cohort used is a group of patients that was referred to a specialty clinic. Any prediction scheme would need to be validated in a cohort of patients that includes all NBPP patients and is unbiased by referral prior to being considered useful by potential referring physicians (such as pediatricians, obstetricians, and family practice physicians). Second, such a prediction scheme may allow nerve surgeons to make an earlier determination as to which infants may benefit from surgical exploration/reconstruction. Nerve surgery is typically performed between 3 and 6 months of life, but early repair is associated with better outcomes..$^{22,24,38}$ Thus, anything that expedites decision making and allows for earlier intervention is likely to improve outcomes.

Our current study identifies the peripartum and neonatal factors that are associated with NBPP persistence. We believe that the incorporation of the peripartum and

TABLE 3. Evaluation of the associations of the neonatal factors with NBPP persistence at 1 year*

\begin{tabular}{lccr}
\hline \multicolumn{1}{c}{ Variable } & $\begin{array}{c}\text { Persistent NBPP } \\
(\mathrm{n}=323)\end{array}$ & $\begin{array}{c}\text { Resolved } \\
\text { NBPP }(\mathrm{n}=59)\end{array}$ & $\mathrm{p}$ Value \\
\hline Apgar score $<7$ at 5 mins & $29 / 160(18.1 \%)$ & $2 / 40(5.0 \%)$ & 0.040 \\
\hline Birth weight $>9$ Ibs & $136 / 307(44.3 \%)$ & $9 / 54(16.7 \%)$ & $<0.001$ \\
\hline Clavicle fracture & $26 / 314(8.3 \%)$ & $5 / 57(8.8 \%)$ & 0.902 \\
\hline Humerus fracture & $21 / 314(6.7 \%)$ & $3 / 57(5.3 \%)$ & 0.999 \\
\hline Torticollis & $136 / 323(42.1 \%)$ & $26 / 59(44.1 \%)$ & 0.779 \\
\hline Plagiocephaly & $89 / 323(27.6 \%)$ & $20 / 59(33.9 \%)$ & 0.321 \\
\hline Horner syndrome present & $43 / 323(13.3 \%)$ & $0 / 59(0.0 \%)$ & $<0.001$ \\
\hline Narakas grade & & & $<0.001$ \\
\hline$\quad$ Grade I-II & $144 / 275(52.4 \%)$ & $33 / 39(84.6 \%)$ & \\
\hline$\quad$ Grade III-IV & $131 / 275(47.6 \%)$ & $6 / 39(15.4 \%)$ & \\
\hline Mean gestational age in & $39.1(1.8)$ & $39.3(1.4)$ & 0.436 \\
wks (SD) & & & \\
\hline
\end{tabular}

* Denominators represent the number of patients for whom data were available for the given variable. neonatal factors into a prediction scheme may be important, but, until now, no data were available regarding the relationship of such factors to the persistence of NBPP. The advantage of identifying such factors is that they can be assessed in the early days of life. Thus, this should allow for the early application of a prediction algorithm and stratification of patients with NBPP that is likely to spontaneously resolve or likely to persist and would benefit from nerve surgery. This would represent a marked paradigm shift, as most management strategies currently rely on the findings at 3 to 6 months of life, which delays intervention.

A number of factors have been suggested that may increase the incidence of NBPP. These include advanced maternal age, obesity, diabetes, abnormalities of second-stage labor, vacuum- or forceps-assisted delivery, and shoulder dystocia. ${ }^{20,27,28,40,43}$ Factors that have been suggested to be protective against NBPP include twin or multiple births and cesarean delivery. ${ }^{16}$ Though this wide range of factors has been suggested, none have been consistently shown to be predictive of NBPP occurrence. We did find that these factors were common in our cohort of patients: $23.8 \%$ of infants had mothers with gestational diabetes; shoulder dystocia was present in $64.9 \%$ of infants; an assistive device such as a vacuum or forceps was used in $22.3 \%$ of births; and the route of delivery was cesarean section in $7.9 \%$ of births. While not uncommon, most of these factors were still present in the minority of cases. Regardless,

TABLE 4. Univariate logistic regression modeling of the factors associated with NBPP persistence at 1 year

\begin{tabular}{llr}
\hline \multicolumn{1}{c}{ Variable } & Odds Ratio $(95 \% \mathrm{Cl})$ & p Value \\
\hline Cephalic presentation & $3.785(1.416-10.122)$ & 0.008 \\
\hline Induction/augmentation & $2.530(1.346-4.755)$ & 0.004 \\
\hline Birth aid used & $2.280(0.991-5.241)$ & 0.052 \\
\hline Cesarean delivery & $0.231(0.105-0.511)$ & $<0.001$ \\
\hline Birth weight $>9$ Ibs & $3.977(1.878-8.421)$ & $<0.001$ \\
\hline Apgar score $<7$ at 5 mins & $4.206(0.960-18.435)$ & 0.057 \\
\hline Horner syndrome & $8.850(1.194-65.585)$ & 0.033 \\
\hline Narakas Grade I-II & $0.200(0.081-0.492)$ & $<0.001$ \\
\hline
\end{tabular}


incidence and persistence have never been linked and no data exist regarding the factors that increase or decrease the likelihood of persistence aside from the Narakas classification.

Narakas classified NBPP into 4 grades. Patients in Grade I have injury to C-5 and C-6 (upper trunk), resulting in weakness of shoulder abduction, external rotation, and elbow flexion. Those in Grade II also have injury to C-7 (middle trunk) with additional weakness of the elbow, wrist, and finger extension. Patients in Grade III have a pan-plexopathy with injury to C-5, C-6, C-7, C-8, and T-1 and a flail arm. Patients in Grade IV have injuries similar to Grade III, but also have Horner syndrome. ${ }^{25,26,41}$ Narakas Grade I to II patients have been shown to have a higher likelihood of spontaneous recovery. ${ }^{15}$ Our data support this finding. We found that infants with Narakas Grade I to II injuries had an odds ratio of 0.200 (95\% CI 0.081-0.492) of persistence compared with Narakas Grade III to IV injuries.

The factors identified in this study as increasing the likelihood of persistence are similar to those previously suggested to increase the incidence of NBPP. We found that cephalic presentation, induction or augmentation of labor, birth weight $>9 \mathrm{lbs}$, and the presence of Horner syndrome increased the risk of persistence, while cesarean delivery and Narakas Grade I to II injury decreased the likelihood. We are the first to identify any peripartum and neonatal factors related to persistence of NBPP. Not all data points were available for all patients, making multivariate analysis difficult. Thus, it remains possible that there is an interaction between some of these identified factors. For example, it remains possible that cephalic presentation simply increases the likelihood of vaginal delivery and really is a covariate with vaginal/cesarean delivery. The inclusion of Horner syndrome was a builtin positive control. Physiologically, the presence of Horner syndrome suggests a very proximal injury to the lower roots that will not spontaneously recover. Thus, the identification of Horner syndrome, by increasing the likelihood of persistence, adds some internal validity to the data.

The lack of an association between shoulder dystocia and NBPP persistence is unexpected because some investigators purport that the persistence of brachial palsy can occur only in conjunction with impacted shoulder. ${ }^{18,19}$ It is possible that there was recall bias by mothers who were not informed of shoulder dystocia by the clinicians. Optimally, we would have the obstetric charts for all children with NBPP in order to confirm if the delivery was complicated by shoulder dystocia. But, it is noteworthy that documentation about shoulder dystocia is not accurate at times, so even if we had the obstetric charts, we could not be certain of whether there was impaction of the shoulder..$^{12,13}$ Moreover, in the postpartum period, neither the clinician nor the mother could have known if NBPP would persist. Thus, it is unlikely that maternal recall could have nullified the association between shoulder dystocia and persistent NBPP. As noted by the American College of Obstetricians and Gynecologists (ACOG), it is likely that NBPP is secondary to maternal endogenous forces of labor in combination with normal exogenous forces applied by the clinician to effectuate delivery. ${ }^{1}$ Indeed, our finding that shoulder dystocia occurred with similar frequencies in the transient and persistent groups supports the suggestion by ACOG that it is the combination of endogenous and exogenous forces that are linked with NBPP.

The major limitation of the study is the selection bias introduced by the cohort used in the study. There was a significant selection bias introduced by the fact that the study cohort is a cohort of patients referred to a specialty clinic. Those patients who quickly and spontaneously recover are unlikely to be captured in this cohort. This is evidenced by the high rate of persistence observed in our cohort $(84.6 \%)$. While there is certainly selection bias in our study, the factors identified are still predictive of persistence, even among a cohort with a high rate of persistence. Future studies should focus on capturing all births within a health care network and then prospectively tracking those with NBPP in order to reduce such bias.

The strengths of this study lie in the patient cohort. First, it is a large cohort, particularly for NBPP studies. Second, the cohort of patients received reliable follow-up for 1 year following birth. Third, both neonates with spontaneous resolution and persistent NBPP were followed for this duration. Fourth, the data set has some evidence of validity, given the aforementioned predictive nature of the presence of Horner syndrome.

\section{Conclusions}

Given the strengths of this study, we believe this study adds to the current body of knowledge surrounding NBPP, particularly as it relates to persistence. Future work will focus on the incorporation of these identified peripartum and neonatal factors into a prediction scheme for persistent NBPP and validating the score of our internal data and subsequently an external data set.

\section{Acknowledgments}

We acknowledge Connie McGovern and Miriana Popadich for their help in the collection of the patient records used in this study. We also acknowledge Holly Wagner for her help with editing and formatting the manuscript for submission.

\section{References}

1. American College of Obstetricians and Gynecologists: Executive summary: Neonatal brachial plexus palsy. Report of the American College of Obstetricians and Gynecologists' Task Force on Neonatal Brachial Plexus Palsy. Obstet Gynecol 123:902-904, 2014

2. Bade SA, Lin JC, Curtis CG, Clarke HM: Extending the indications for primary nerve surgery in obstetrical brachial plexus palsy. BioMed Res Int 2014:627067, 2014

3. Bager B: Perinatally acquired brachial plexus palsy-a persisting challenge. Acta Paediatr 86:1214-1219, 1997

4. Bertelli JA, Ghizoni MF: The towel test: a useful technique for the clinical and electromyographic evaluation of obstetric brachial plexus palsy. J Hand Surg Br 29:155-158, 2004

5. Bisinella GL, Birch R, Smith SJ: Neurophysiological prediction of outcome in obstetric lesions of the brachial plexus. $\mathbf{J}$ Hand Surg Br 28:148-152, 2003

6. Borschel GH, Clarke HM: Obstetrical brachial plexus palsy. Plast Reconstr Surg 124 (1 Suppl):144e-155e, 2009

7. Brody IA, Wilkins RH: Erb's palsy. Arch Neurol 21:442444, 1969

8. Brown SH, Noble BC, Yang LJ, Nelson VS: Deficits in elbow 
position sense in neonatal brachial plexus palsy. Pediatr Neurol 49:324-328, 2013

9. Chang KW, Justice D, Chung KC, Yang LJ: A systematic review of evaluation methods for neonatal brachial plexus palsy: a review. J Neurosurg Pediatr 12:395-405, 2013

10. Chang KW, Yang LJ, Driver L, Nelson VS: High prevalence of early language delay exists among toddlers with neonatal brachial plexus palsy. Pediatr Neurol 51:384-389, 2014

11. Dawodu A, Sankaran-Kutty M, Rajan TV: Risk factors and prognosis for brachial plexus injury and clavicular fracture in neonates: a prospective analysis from the United Arab Emirates. Ann Trop Paediatr 17:195-200, 1997

12. Deering S, Poggi S, Hodor J, Macedonia C, Satin AJ: Evaluation of residents' delivery notes after a simulated shoulder dystocia. Obstet Gynecol 104:667-670, 2004

13. Deering SH, Tobler K, Cypher R: Improvement in documentation using an electronic checklist for shoulder dystocia deliveries. Obstet Gynecol 116:63-66, 2010

14. Evans-Jones G, Kay SP, Weindling AM, Cranny G, Ward A, Bradshaw A, et al: Congenital brachial palsy: incidence, causes, and outcome in the United Kingdom and Republic of Ireland. Arch Dis Child Fetal Neonatal Ed 88:F185-F189, 2003

15. Foad SL, Mehlman CT, Foad MB, Lippert WC: Prognosis following neonatal brachial plexus palsy: an evidence-based review. J Child Orthop 3:459-463, 2009

16. Foad SL, Mehlman CT, Ying J: The epidemiology of neonatal brachial plexus palsy in the United States. J Bone Joint Surg Am 90:1258-1264, 2008

17. Gilbert A, Tassin JL: [Surgical repair of the brachial plexus in obstetric paralysis.] Chirurgie 110:70-75, 1984 (Fr)

18. Gurewitsch ED, Allen RH: Reducing the risk of shoulder dystocia and associated brachial plexus injury. Obstet Gynecol Clin North Am 38:247-269, x, 2011

19. Gurewitsch ED, Johnson E, Hamzehzadeh S, Allen RH: Risk factors for brachial plexus injury with and without shoulder dystocia. Am J Obstet Gynecol 194:486-492, 2006

20. Hudić I, Fatusić Z, Sinanović O, Skokić F: Etiological risk factors for brachial plexus palsy. J Matern Fetal Neonatal Med 19:655-661, 2006

21. Kawabata H, Masada K, Tsuyuguchi Y, Kawai H, Ono K, Tada R: Early microsurgical reconstruction in birth palsy. Clin Orthop Relat Res (215):233-242, 1987

22. Malessy MJ, Pondaag W: Nerve surgery for neonatal brachial plexus palsy. J Pediatr Rehabil Med 4:141-148, 2011

23. Malessy MJ, Pondaag W, van Dijk JG: Electromyography, nerve action potential, and compound motor action potentials in obstetric brachial plexus lesions: validation in the absence of a "gold standard". Neurosurgery 65 (4 Suppl):A153A159, 2009

24. Malessy MJ, Pondaag W, Yang LJ, Hofstede-Buitenhuis SM, le Cessie S, van Dijk JG: Severe obstetric brachial plexus palsies can be identified at one month of age. PLoS One 6:e26193, 2011

25. Narakas AO: Injuries to the brachial plexus, in Bora FWJ (ed): The Pediatric Upper Extremity: Diagnosis and Management. Philadelphia: W. B. Saunders, 1986, pp 247-258

26. Narakas AO: Obstetrical brachial plexus injuries, in Lamb DW (ed): The Paralysed Hand. New York: Churchill Livingstone, 1987, Vol. 2, pp 116-135

27. Okby R, Sheiner E: Risk factors for neonatal brachial plexus paralysis. Arch Gynecol Obstet 286:333-336, 2012

28. Ouzounian JG: Risk factors for neonatal brachial plexus palsy. Semin Perinatol 38:219-221, 2014

29. Pondaag W, de Boer R, van Wijlen-Hempel MS, HofstedeBuitenhuis SM, Malessy MJ: External rotation as a result of suprascapular nerve neurotization in obstetric brachial plexus lesions. Neurosurgery 57:530-537, 2005

30. Pondaag W, Malessy MJ: Recovery of hand function following nerve grafting and transfer in obstetric brachial plexus lesions. J Neurosurg 105 (1 Suppl):33-40, 2006
31. Pondaag W, Malessy MJ, van Dijk JG, Thomeer RT: Natural history of obstetric brachial plexus palsy: a systematic review. Dev Med Child Neurol 46:138-144, 2004

32. Somashekar D, Yang LJ, Ibrahim M, Parmar HA: High-resolution MRI evaluation of neonatal brachial plexus palsy: A promising alternative to traditional CT myelography. AJNR Am J Neuroradiol 35:1209-1213, 2014

33. Squitieri L, Larson BP, Chang KW, Yang LJ, Chung KC: Understanding quality of life and patient expectations among adolescents with neonatal brachial plexus palsy: a qualitative and quantitative pilot study. J Hand Surg Am 38:2387-2397, 2397.e1-2397.e2, 2013

34. Squitieri L, Steggerda J, Yang LJ, Kim HM, Chung KC: A national study to evaluate trends in the utilization of nerve reconstruction for treatment of neonatal brachial plexus palsy. Plast Reconstr Surg 127:277-283, 2011

35. Tse R, Nixon JN, Iyer RS, Kuhlman-Wood KA, Ishak GE: The diagnostic value of CT myelography, MR myelography, and both in neonatal brachial plexus palsy. AJNR Am J Neuroradiol 35:1425-1432, 2014

36. van Ouwerkerk WJ, van der Sluijs JA, Nollet F, Barkhof F, Slooff AC: Management of obstetric brachial plexus lesions: state of the art and future developments. Childs Nerv Syst 16:638-644, 2000

37. Vanderhave KL, Bovid K, Alpert H, Chang KW, Quint DJ, Leonard JA Jr, et al: Utility of electrodiagnostic testing and computed tomography myelography in the preoperative evaluation of neonatal brachial plexus palsy. J Neurosurg Pediatr 9:283-289, 2012

38. Waters PM: Comparison of the natural history, the outcome of microsurgical repair, and the outcome of operative reconstruction in brachial plexus birth palsy. J Bone Joint Surg Am 81:649-659, 1999

39. Waters PM: Obstetric brachial plexus injuries: evaluation and management. J Am Acad Orthop Surg 5:205-214, 1997

40. Weizsaecker K, Deaver JE, Cohen WR: Labour characteristics and neonatal Erb's palsy. BJOG 114:1003-1009, 2007

41. Yang LJ: Neonatal brachial plexus palsy-management and prognostic factors. Semin Perinatol 38:222-234, 2014

42. Yoshida K, Kawabata H: The prognostic value of concurrent phrenic nerve palsy in newborn babies with neonatal brachial plexus palsy. J Hand Surg Am 40:1166-1169, 2015

43. Zuarez-Easton S, Zafran N, Garmi G, Nachum Z, Salim R: Are there modifiable risk factors that may predict the occurrence of brachial plexus injury? J Perinatol 35:349-352, 2015

\section{Disclosures}

The authors report no conflict of interest concerning the materials or methods used in this study or the findings specified in this paper.

\section{Author Contributions}

Conception and design: Yang, Wilson, Chauhan. Acquisition of data: Yang, Wilson, Chang. Analysis and interpretation of data: all authors. Drafting the article: Yang, Wilson, Chang. Critically revising the article: all authors. Reviewed submitted version of manuscript: all authors. Approved the final version of the manuscript on behalf of all authors: Yang. Statistical analysis: Yang, Wilson, Chang. Study supervision: Yang, Wilson.

\section{Correspondence}

Lynda J. S. Yang, Department of Neurosurgery, University of Michigan, 1500 E. Medical Center Dr., 3552 Taubman Center, Ann Arbor, MI, 48109-5338. email: ljsyang@med.umich.edu. 